\title{
0 \\ IJCRR \\ Section: Healthcare \\ Ethanol, Methanol, and Magnesium-Treated Palm Kernel Shell Biochar for Methylene Blue Removal: Adsorption Isotherms
}

ISI Impact Factor

(2019-20): 1.628

IC Value (2019): 90.81

SJIF (2020) $=7.893$

(c) (i) (8)

\section{Hasana NH, Wahi R, Yusof Y}

Faculty of Resource Science and Technology, Universiti Malaysia Sarawak, 94300 Kota Samarahan, Sarawak, Malaysia.

\section{ABSTRACT}

Introduction: Biochar's adsorbent attributes, for instance, surface area, porous structure, surface functionality, and adsorption capacity, can be enhanced via suitable chemical modification.

Objective: This work aimed to study the effect of ethanol (EtOH), methanol $(\mathrm{MeOH})$, and magnesium (Mg) treatment on adsorbent properties of palm kernel shell (PKS) biochar.

Methods: The PKS biochar was obtained through fast carbonization in a rotary kiln $\left(800^{\circ} \mathrm{C}, 10 \mathrm{~min}\right)$ followed by steam activation $(8 \mathrm{~h})$. Both the $\mathrm{EtOH}$ and $\mathrm{MeOH}$ treated biochar were afforded via $\mathrm{EtOH}$ and $\mathrm{MeOH}$ treatment of PKS biochar, respectively, in the presence of $\mathrm{HCl}(6 \mathrm{~h})$, followed by rinsing, filtering, and oven-drying. Mg treated biochar was obtained by soaking the PKS biochar with $\mathrm{MgSO}_{4} .7 \mathrm{H}_{2} \mathrm{O}$ at $30^{\circ} \mathrm{C}$ for $60 \mathrm{~h}$. The $\mathrm{EtOH}, \mathrm{MeOH}$, and $\mathrm{Mg}$ treated biochars were characterized via proximate analysis, functional group analysis, surface area, and pore volume analyses. A batch adsorption study was conducted for adsorption of methylene blue (MB) by each $\mathrm{EtOH}, \mathrm{MeOH}$, and $\mathrm{Mg}$ treated biochar, respectively.

Results: Brunauer-Emmett-Teller (BET) analysis indicated that carbonization and chemical treatment has successfully enhanced the surface area with raw PKS $\left(0.848 \mathrm{~m}^{2} \mathrm{~g}^{-1}\right)$, PKS biochar $\left(592 \mathrm{~m}^{2} \mathrm{~g}^{-1}\right)$, EtOH-treated biochar $\left(647 \mathrm{~m}^{2} \mathrm{~g}^{-1}\right), \mathrm{MeOH}$-treated biochar $\left(663 \mathrm{~m}^{2} \mathrm{~g}^{-1}\right)$, and Mg-treated biochar $\left(674 \mathrm{~m}^{2} \mathrm{~g}^{-1}\right)$. Batch adsorption studies showed that the highest methylene blue (MB) removal percentage for all studied biochar occurred at an initial concentration of 7 ppm (PKS biochar: $93.12 \%$, EtOH-treated PKS biochar: 94.79\%, MeOH-treated PKS biochar: 95.79\%, and Mg-treated PKS biochar: 98.51\%).

Conclusion: The $\mathrm{EtOH}, \mathrm{MeOH}$, and $\mathrm{Mg}$ treated PKS biochar gave high MB removal and thus, could potentially serve as efficient adsorbents for removal of dyes from wastewater.

Key Words: Carbonization, Biochar, Palm kernel shell, Chemical treatment, Engineered biochar

\section{INTRODUCTION}

Over 700000 tonnes of commercial dyes are made per annum, for usage in fabrics, paper, plastic, leather, and chemical industries. ${ }^{1,2}$ Consequently, approximately $10-15 \%$ of dyes used in the afore-mentioned industries are discharged as industrial effluent annually. ${ }^{3}$ Severe dye pollution could cause coloured water that prevents solar radiation from entering water sources and inhibits the photosynthesis of aquatic biota. ${ }^{4}$ Considering the globally high volume of dye production and usage, proper treatments are needed in favour of reducing the ramification of dye pollution in the ecosystem.

Methylene blue (MB) is one of the basic dyes usually applied in industries such as colouring paper, hair dye, dyeing cotton, wools, and others. ${ }^{5} \mathrm{MB}$ (a thiazine cationic dye) can pose numerous detrimental effects such as complications in breathing, retching, nausea, gastritis, and diarrhoea, to living things. ${ }^{6}$ Moreover, MB can also cause permanent eye injury to humans and animals. ${ }^{7}$ Inhaling MB can lead to cyanosis, methemoglobinemia, dyspnoea, convulsions, and tachycardia. ${ }^{8}$ Hence, MB removal from wastewater before liberating it to water bodies is crucial in protecting human health.

Various techniques such as adsorption, ion exchange, reverse osmosis, and solvent extraction have been developed to remove dyes from wastewaters, including MB.$^{5,9}$ Among these methods, adsorption is the most preferred approach in eliminating organic contaminants from aqueous solution as it has been proven to be effective, low cost, and gives high removal

\section{Corresponding Author:}

Rafeah Wahi, Faculty of Resource Science and Technology, Universiti Malaysia Sarawak, 94300 Kota Samarahan, Sarawak, Malaysia. Email:wrafeah@unimas.my

ISSN: 2231-2196 (Print)

Received: 07.09 .2020
ISSN: 0975-5241 (Online)

Revised: 14.10 .2020
Accepted: 16.11 .2020
Published: 23.02 .2021 
capacity. ${ }^{10}$ Adsorption of organic and inorganic pollutants, including dyes using biochar, has been applied for many years as its specific properties are fit for sorbent materials such as vast distinct surface area, porous structure, enhanced surface functionality, and mineral components. ${ }^{11}$

However, biochar's adsorbent properties can be further enhanced via suitable chemical modification. Numerous studies have been accomplished on the usage of chemically modified biochar in removing MB. Jawad et al. ${ }^{1}$ focused on the utilization of sulfuric acid-treated coconut leaf biochar to remove MB. Mohan and Chadaga ${ }^{12}$ studied MB removal using cashew nutshell biochar, which was treated with sulfuric acid and hydrogen peroxide. Research has experimented using phosphoric acid-treated PKS biochar to adsorb MB from an aqueous solution. ${ }^{13}$ Most of the previous studies focused on treating biochar using acids or bases but rarely alcohols and minerals. Thus, this research aims to learn the nature of chemically treated palm kernel shell (PKS) biochar, namely the EtOH-treated PKS biochar, MeOH-treated PKS biochar, and $\mathrm{Mg}$-treated biochar for the removal of MB from aqueous solution. The efficiency of MB removal from aqueous solution by the treated biochar was studied in the context of various adsorption isotherms (Langmuir and Freundlich isotherms).

\section{MATERIALS AND METHODS}

\section{Sample Pre-treatment}

Raw PKS and PKS biochar were collected from Bravo Green Sdn. Bhd. The biochar was obtained through carbonization in a rotary kiln $\left(800{ }^{\circ} \mathrm{C}, 10 \mathrm{~min}\right)$ followed by steam activation $(8 \mathrm{~h})$. The raw and biochar samples were washed, sundried, ground into powder, and sieved into $2.0 \mathrm{~mm}$ and 0.5 $\mathrm{mm}$ particle size.

\section{EtOH and MeOH Treatment}

PKS biochar ( $5 \mathrm{~g}, 0.5 \mathrm{~mm}$ ) was added to $\mathrm{MeOH}$ (SigmaAldrich, Germany, $500 \mathrm{ml}$ ) and concentrated $\mathrm{HCl}$ (R\&M Chemicals, Malaysia, 32\%, $4.15 \mathrm{ml}) .^{14,15}$ The mixture was agitated on a rotary shaker $(6 \mathrm{~h}, 130 \mathrm{rpm})$ before the treated biochar was rinsed, filtered off, and oven-dried $\left(60{ }^{\circ} \mathrm{C}, 24\right.$ h).$^{16}$ The method was repeated using ethanol (HmBG Chemicals, Malaysia, $500 \mathrm{ml}$ ).

\section{Mg Treatment}

The biochar was cleaned with distilled water to eliminate impurities and desiccated before $\mathrm{Mg}$ treatment. PKS biochar $\left(20 \mathrm{~g}, 0.5 \mathrm{~mm}\right.$ ) were soaked in $\mathrm{MgSO}_{4} \cdot 7 \mathrm{H}_{2} \mathrm{O}$ (Ajax Finechem Pty Ltd, Australia, $500 \mathrm{ml}$ ) at $30^{\circ} \mathrm{C}$ for $60 \mathrm{~h}^{17}$. The PKS biochar was then vacuum-filtered, oven-dried $\left(90^{\circ} \mathrm{C}\right.$, $12 \mathrm{~h}$ ), and pyrolyzed at $500{ }^{\circ} \mathrm{C}$ for $30 \mathrm{~min}^{16,17}$ The cooled biochar was rinsed once again with distilled water to get rid of impurities.

\section{Characterization of Adsorbent}

The evaluation for moisture content, volatile matter, ash content, fixed carbon in PKS, and chemically treated biochar were determined through proximate analysis based on its applicable standards: ASTM D3173, ASTM D3174, and ASTM D3175. The surface area and pore volume of the biochar were determined using the Brunauer-Emmett-Teller (BET) technique via Surface Area Analyzer (Quantachrome $\mathbb{R}$ ASiQwin $^{\mathrm{TM}}$, United States) with nitrogen adsorption technique. ${ }^{18}$ This method was executed by operating purified $\mathrm{N}_{2}$ on the biochar followed by heating the sample $\left(200{ }^{\circ} \mathrm{C}, 8 \mathrm{~h}\right)$ under vacuum conditions. The nitrogen gas was sanctioned to be aerated through the sample after the heating process. Then the surface area of biochar will be figured out by computing the isotherm of biochar towards the $\mathrm{N}_{2} \cdot{ }^{19}$ The functional groups of the PKS biochar were evaluated via Fourier Transform Infrared Spectroscopy (FTIR) (Thermo Nicolet Is10, United States) analysis.

\section{Adsorption Studies}

Stock Solution Preparation: MB stock solution (Bendosen, Malaysia) was concocted by placing MB (1 g) in deionized water $(1000 \mathrm{ml})$ to get $1000 \mathrm{ppm}$ concentration. ${ }^{20}$ The MB concentration was investigated by a UV/Vis spectrophotometer (JASCO V-730, Japan) at a wavelength of $665 \mathrm{~nm}$. Calibration was conducted using 1, 2, 3, 4, 5, 6, and $7 \mathrm{ppm} \mathrm{MB}$ solution. ${ }^{21}$

Batch Adsorption Studies: The effects of MB initial concentration and adsorbent dosage on MB adsorption using untreated and treated biochars were studied using the batch adsorption method. The amount of MB absorbed at equilibrium, $\mathrm{q}_{\mathrm{e}}(\mathrm{mg} / \mathrm{g})$, was computed by using Eq. ${ }^{22}$ :

$$
q_{e}=\left(\frac{\left(C_{0}-C_{e}\right) V}{W}\right)
$$

Whereas, the adsorption efficiency (\%) of MB was determined by using Eq. $2^{22}$ :

Percentageremoval $(\%)=\left(\frac{\left(C_{0}-C_{e}\right)}{C_{0}} \times 100\right)$

where $\mathrm{C}_{0}=$ initial concentration of $\mathrm{MB}(\mathrm{mg} / \mathrm{l}), \mathrm{C}_{\mathrm{e}}=$ equilibrium concentration in liquid phase $(\mathrm{mg} / \mathrm{l}), \mathrm{V}=$ volume of solution, and $\mathrm{W}=$ mass of adsorbent

The effects of initial concentrations on $\mathrm{MB}$ removal were explored using MB solution $(100 \mathrm{ml})$ at a different initial concentration $(1,2,3,4,5,6 \text {, and } 7 \mathrm{ppm})^{23}$ with no $\mathrm{pH}$ modification. ${ }^{24}$ EtOH-treated PKS biochar $(0.5 \mathrm{~g}), \mathrm{MeOH}-$ treated PKS biochar $(0.5 \mathrm{~g})$, and Mg-treated PKS biochar $(0.5 \mathrm{~g})$ were added to MB mixtures, respectively. The effect of contact time on MB removal was planned at 5, 15, 30, 45, and $60 \mathrm{~min}$. EtOH-treated PKS biochar $(0.5 \mathrm{~g}), \mathrm{MeOH}-$ 
treated PKS biochar $(0.5 \mathrm{~g})$, and Mg-treated PKS biochar $(0.5 \mathrm{~g})$ were added to $\mathrm{MB}$ solution $(3 \mathrm{ppm}, 100 \mathrm{ml})$, respectively. The mixture was shaken $(150 \mathrm{rpm}, 30 \mathrm{~min})$ to reach equilibrium and filtered. The final MB concentration was computed and obtained by using UV-Vis.

$$
\frac{C_{e}}{q_{e}}=\frac{1}{q_{\max }} C_{e}+\frac{1}{K_{L} q_{\max }}
$$

Equilibrium Adsorption Isotherms: Adsorption isotherms are applied to illustrate the correlation between the adsorbed concentration and the dissolved concentration at equilibrium and describe a particular interaction between adsorbent and adsorbate at a given environmental condition. ${ }^{24,25}$ In this study, the relevancy of Langmuir and Freundlich isotherms equations were contrasted by estimating the value of correlation coefficients, $\mathrm{R}^{2}$. The isotherm graph was plotted by using initial concentration data. Langmuir isotherm was initially introduced to illustrate gas-solid adsorption onto adsorbents, has been utilized to measure and compare the achievement of various adsorbents. ${ }^{26}$ This isotherm operates based on the supposition that monolayer adsorption occurs with homogenous binding sites and energy levels and no interactions between adsorbed particles. ${ }^{22}$ Langmuir equation in linear form is as in Eq. 3:

where, $\mathrm{C}_{\mathrm{e}}=$ equilibrium concentration in liquid phase ( $\left.\mathrm{mg} / \mathrm{L}\right)$, $\mathrm{q}_{\mathrm{e}}=$ equilibrium concentration in adsorbed phase $(\mathrm{mmol} / \mathrm{g})$, $\mathrm{q}_{\max }=$ Langmuir constants representing the adsorption capacity $(\mathrm{mg} / \mathrm{g})$, and $\mathrm{K}_{\mathrm{L}}$ : Langmuir constant $(\mathrm{L} / \mathrm{mg})$. A straight line with slope $\left(1 / \mathrm{q}_{\max }\right)$ and intercept $\left(1 / \mathrm{K}_{\mathrm{L}} \mathrm{q}_{\max }\right)$ could be achieved by plotting $\mathrm{C}_{\mathrm{e}} / \mathrm{q}_{\mathrm{e}}$ versus $\mathrm{C}_{\mathrm{e}}{ }^{27}$.

Freundlich isotherm is a factual equation that is dependent on a heterogeneous surface ${ }^{27}$. This isotherm can depict the adsorption of organic and inorganic compounds on various adsorbents ${ }^{19}$. Freundlich isotherm can be conveyed in linear form (Eq. 4):

$$
\log q_{e}=\log K_{F}+\frac{1}{n} \log C_{e}
$$

where, $\mathrm{q}_{\mathrm{e}}=$ amount of $\mathrm{MB}$ adsorbed at equilibrium time ( $\mathrm{mmol} / \mathrm{g}), \mathrm{K}_{\mathrm{F}}, \mathrm{n}=$ Freundlich constants, and $\mathrm{C}_{\mathrm{e}}=$ Equilibrium concentration $(\mathrm{mg} / \mathrm{L}) . \mathrm{K}_{\mathrm{F}}$ indicates the adsorption capacity, and $\mathrm{n}$ indicates the adsorption intensity. Freundlich constants can be acquired from the slope $(1 / n)$ and intercept $\left(\log K_{F}\right)$ of the linear plot by plotting $\log \mathrm{q}_{\mathrm{e}} \mathrm{vs} . \log \mathrm{C}_{\mathrm{e}}{ }^{27}$.

\section{RESULTS}

Figure 1 shows the proximate analysis of the studied samples. All treated biochar showed higher moisture content compared to untreated biochar: EtOH-treated PKS biochar (17.56\%), MeOH-treated PKS biochar (14.92\%), and Mg- treated PKS biochar (19.28\%). Mg-treated biochar has the highest ash content $(28.48 \%)$ compared to other treated biochars, which are likely due to the addition of $\mathrm{Mg}$ minerals in the biochar. ${ }^{17}$ The ash content percentage agrees with previous works on Mg-treated biochar for sugarcane bagasse biochar $(20.64 \%)^{28}$ and switchgrass biochar $(28.4 \%) .{ }^{29}$ Raw PKS displayed the highest volatile matter $(75.58 \%)$ then followed by untreated PKS biochar (45.91\%), EtOH-treated PKS biochar (26.87\%), MeOH-treated PKS biochar (19.26\%), and $\mathrm{Mg}$-treated biochar (14.26\%). The untreated biochar with the fixed carbon of $11.84 \%$ is significantly lower than the fixed carbon of treated biochar. EtOH-treated biochar exhibits the highest percentage of fixed carbon $(41.90 \%)$, followed by $\mathrm{MeOH}$-treated biochar (39.34\%) and Mg-treated biochar (37.97\%). Raw PKS has the lowest selected carbon content, which is $2.21 \%$. The surface area of PKS biochar was notably amplified after carbonization, from $0.848 \mathrm{~m}^{2} \mathrm{~g}^{-1}$ to 592 $\mathrm{m}^{2} \mathrm{~g}^{-1}$, and further increased after chemical treatment (Table 1). EtOH-treated biochar has a smaller surface area $\left(647 \mathrm{~m}^{2} \mathrm{~g}\right.$ 1) than $\mathrm{MeOH}$-treated biochar $\left(663 \mathrm{~m}^{2} \mathrm{~g}^{-1}\right)$. Mg-treated PKS biochar was able to show the highest surface area, which is $674 \mathrm{~m}^{2} \mathrm{~g}^{-1}$.

The simplified FTIR results of raw PKS, untreated PKS biochar, EtOH-treated PKS biochar, MeOH-treated PKS biochar, and Mg-treated PKS biochar are shown in Table 2. From the table, the band peaks at $3452.86 \mathrm{~cm}^{-1}, 3449.85$ $\mathrm{cm}^{-1}, 3452.82 \mathrm{~cm}^{-1}, 3453.87 \mathrm{~cm}^{-1}$, and $3455.23 \mathrm{~cm}^{-1}$ for raw PKS, untreated PKS biochar, EtOH-treated PKS biochar, $\mathrm{MeOH}$-treated PKS biochar, and Mg-treated PKS biochar, respectively, correspond to $\mathrm{O}-\mathrm{H}$ stretching vibrations demonstrating the existence of chemical complexes like alcohol, phenol, or carboxylic acid. ${ }^{30}$ However, for the case of EtOH-treated PKS biochar and MeOH-treated PKS biochar, there is a significant shift for hydroxyl groups where after the treatment, from $3449.85 \mathrm{~cm}^{-1}$ (untreated PKS biochar), it increased to $3452.82 \mathrm{~cm}^{-1}$ and $3453.87 \mathrm{~cm}^{-1}$, for EtOH-treated PKS biochar and $\mathrm{MeOH}$-treated PKS biochar, respectively, indicating the multiplication of hydroxyl groups in both biochars $^{14}$. A sequence of peaks at $800-400 \mathrm{~cm}^{-1}$ in the case of $\mathrm{Mg}$-treated biochar can be attributed to $\mathrm{Mg}-\mathrm{O}$ and $\mathrm{O}-\mathrm{Mg}_{-}$ $\mathrm{O}$, which suggests the presence of $\mathrm{Mg}$ oxyhydroxides. ${ }^{17}$ EtOH-treated PKS biochar and MeOH-treated PKS biochar, the band peaks at $841.64 \mathrm{~cm}^{-1}$, and $840.03 \mathrm{~cm}^{-1}$ can be ascribed to $\mathrm{C}-\mathrm{H}$ in aromatic rings of the biochar. ${ }^{31,32}$ Notably, the $\mathrm{C}-\mathrm{H}\left(-\mathrm{CH}_{2}\right.$ and $\left.-\mathrm{CH}_{3}\right)$ bending vibrations at the peaks ranged from 1407.81 to $1388.26 \mathrm{~cm}^{-1}$ in all samples, possibly indicate the presence of alkanes components.

The percentage removal of MB by untreated PKS biochar appeared to be steadily increasing, starting from the initial concentration of $2 \mathrm{ppm}$ up to $7 \mathrm{ppm}$ (Figure 2). For EtOHtreated PKS biochar, the percentage of removal increased from an initial concentration of $1 \mathrm{ppm}$ to $2 \mathrm{ppm}$ and became constant after that. On the other hand, percentage removal of 
MB by $\mathrm{MeOH}$-treated PKS biochar showed a slight increase from $1 \mathrm{ppm}$ up to $4 \mathrm{ppm}$ and remain constant until $6 \mathrm{ppm}$ and slowly rise again to reach the highest percentage of $95.79 \%$.

The initial concentration of $1 \mathrm{ppm}$ displayed the lowest MB removal percentage for all biochars (untreated PKS biochar: 65.64\%, EtOH-treated PKS biochar: 77.45\%, $\mathrm{MeOH}$-treated PKS biochar: 84.76\%, and Mg-treated PKS biochar: $87.20 \%$ ). The highest MB removal percentage for all studied biochars occurred at the initial concentration of 7 ppm (untreated PKS biochar: 93.12\%, EtOH-treated PKS biochar: $94.79 \%$, MeOH-treated PKS biochar: $95.79 \%$, and Mg-treated PKS biochar: 98.51\%). Based on the statistical analysis of variance (ANOVA), there is a substantial contrast between percentage removal between untreated biochar and treated biochar as the $p$-value is $0.0435(\mathrm{p}<0.05)$. The percentage removal of MB by untreated PKS biochar, EtOH-treated PKS biochar, $\mathrm{MeOH}$-treated PKS biochar, and Mg-treated PKS biochar start to remain constant at $3 \mathrm{ppm}$, which indicates that the optimum initial concentration for all adsorbents is $3 \mathrm{ppm}$.

Figure 3 illustrates that MB removal percentage improved as the contact time increased for all treated PKS biochar. All treated biochar has succeeded in removing more than $90 \%$ of MB for the first 5 min with the same conditions applied to all samples (initial concentration of $3 \mathrm{ppm}$ and dosage of $0.5 \mathrm{~g}$ ). In contrast, the $\mathrm{MB}$ removal percentage for untreated biochar $(87.73 \%)$ is less than $90 \%$. This result follows the outcome for the effect of initial concentration where the MB removal percentage for untreated biochar $(86.89 \%$ ) is less than $90 \%$, while treated biochar showed a high MB removal percentage of more than $90 \%$. The repulsive forces between the ions could instigate the steep decrease, which occurred at $15 \mathrm{~min}$, or the solution could be simply contaminated ${ }^{33}$. The highest percentage of removal for untreated PKS biochar is $91.33 \%$ at $60 \mathrm{~min}$. The highest removal percentages for EtOH-treated PKS biochar, $\mathrm{MeOH}$-treated PKS biochar, and Mg-treated PKS biochar are $96.46 \%, 96.76 \%$, and $96.86 \%$ at $60 \mathrm{~min}$.

Langmuir constants, $\mathrm{q}_{\mathrm{m}}$ (maximum adsorption capacity), and $\mathrm{K}_{\mathrm{L}}$ can be obtained and computed from the slope and intercept of the graph, respectively. Based on Figure 4, the value of $\mathrm{q}_{\mathrm{m}}$ for MB adsorption by untreated PKS biochar is $-0.0863 \mathrm{mg} / \mathrm{g}$, whereas the value of $\mathrm{K}_{\mathrm{L}}$ is $-1.9694 \mathrm{~L} / \mathrm{mg}$. Meanwhile, the value of $\mathrm{q}_{\mathrm{m}}$ for EtOH-treated PKS biochar is $-0.2776 \mathrm{mg} / \mathrm{g}$, and the value of $\mathrm{K}_{\mathrm{L}}$ is $-2.2702 \mathrm{~L} / \mathrm{mg}$. The adsorption of MB by MeOH-treated PKS biochar revealed that the $\mathrm{q}_{\mathrm{m}}$ has a value of $-0.4773 \mathrm{mg} / \mathrm{g}$ and a constant $\mathrm{K}_{\mathrm{L}}$ value of $-2.1893 \mathrm{~L} / \mathrm{mg}$. On the other hand, Mg-treated PKS biochar has the maximum adsorption capacity constant, $\mathrm{q}_{\mathrm{m}}$, of $0.0613 \mathrm{mg} / \mathrm{g}$ and $\mathrm{K}_{\mathrm{L}}$ value of $-10.063 \mathrm{~L} / \mathrm{mg}$. The negative values of $\mathrm{K}_{\mathrm{L}}$ mean that Langmuir isotherm does not fit with the trial data of this study. The value of the coefficient of determination, $\mathrm{R}^{2}$ for $\mathrm{MB}$ adsorption by untreated $\mathrm{PKS}$ biochar is 0.7124 , whereas the value of $\mathrm{R}^{2}$ for EtOH-treated PKS biochar is 0.3507 . Adsorption of $\mathrm{MB}$ by $\mathrm{MeOH}$-treated PKS biochar and Mg-treated PKS biochar displayed $\mathrm{R}^{2}$ of 0.3806 and 0.5669 , respectively.

Linear plot of $\log \mathrm{q}_{\mathrm{e}}$ against $\log \mathrm{C}_{\mathrm{e}}$ (Figure 5) was plotted to analyze the adsorption equilibrium of $\mathrm{MB}$ with untreated PKS biochar, Mg-treated PKS biochar, $\mathrm{MeOH}$-treated PKS biochar, and EtOH-treated PKS biochar. $\mathrm{K}_{\mathrm{F}}$ and $n$ are Freundlich constants that signify adsorption capacity and adsorption intensity, respectively, while $1 / n$ can be ascribed to heterogeneity factor. ${ }^{36}$ Both constants can be determined based on the equation from the graph. The value of $\mathrm{K}_{\mathrm{F}}$ for untreated PKS biochar is $69.231 \mathrm{mg} / \mathrm{g}$, the value of $n$ is 0.1766 , and the $1 / n$ value is 5.5926 . On the other hand, the value of $\mathrm{K}_{\mathrm{F}}, n$, and $1 / n$ for MB adsorption by EtOH-treated PKS biochar is $16.912 \mathrm{mg} / \mathrm{g}, 0.3808$, and 2.6258, respectively. The adsorption of MB by MeOH-treated PKS biochar demonstrated that the value of $\mathrm{K}_{\mathrm{F}}$ is $11.094 \mathrm{mg} / \mathrm{g}$, and the value of $n$ constant is 0.4944 with $1 / n$ of 2.0226. Mg-treated PKS biochar has the adsorption capacity, $\mathrm{K}_{\mathrm{F}}, 2.8536 \times 10^{-6} \mathrm{mg} / \mathrm{g}, n$ value of -0.1764 , and $1 / n$ of -5.6699 .

Table 3 shows that the adsorption characteristics of untreated PKS biochar can be described and explained by Langmuir and Freundlich isotherms since untreated PKS biochar has the highest determination coefficient, $\mathrm{R}^{2}$, in studied isotherm models.

\section{DISCUSSION}

Mg-treated biochar showed the highest moisture content compared to other treated biochar, plausibly resulting from longer soaking time in $\mathrm{MgSO}_{4} \cdot 7 \mathrm{H}_{2} \mathrm{O}$ solution $(60 \mathrm{~h})$ than methanol and ethanol treatment. The moisture content for all biochars is considered low moisture since the percentage is below $40 \%$, whereas high moisture content is more than $40 \% .{ }^{27-29}$ It can be perceived that the moisture content for the treated biochars in this study is measurably higher than other treated biochars such as treated cashew nut shells biochar with a moisture content of $9.83 \% \%^{30,31}$ and moisture content of coconut husk biochar treated with various chemicals which are ranged from 3.48 to $10.59 \% .{ }^{31-33}$ The most likely reason could be the long washing process after being soaked in chemicals. Ash content is incombustible minerals such as calcium, magnesium, iron, sodium, and potassium found in the biomass..$^{34,35,38}$ The high temperature used during the carbonization process was responsible for the volatile matter to discharge from weaker bonds hence being released into the atmosphere. ${ }^{36,37,39}$ High release of volatile matter leads to biochar production with additional new pores, thus improving the surface area of the biochar. ${ }^{40,41}$ Fixed carbon is fundamentally carbon comprised of $\mathrm{O}_{2}, \mathrm{H}_{2}, \mathrm{~N}_{2}$ and $\mathrm{S}$, which are in small quantities. The fixed carbon in the biochar can 
develop the structure of carbons into pores, which further denotes the potential improvement of the adsorption sites of the biochar. ${ }^{30}$

The main characteristics that indicate cellulose, hemicellulose and lignin in the PKS biochar are when the functional groups as $\mathrm{O}-\mathrm{H}, \mathrm{C}-\mathrm{O}, \mathrm{C}=\mathrm{O}$, and $\mathrm{C}-\mathrm{H}$ present in the spectra. ${ }^{31}$ The bands for all biochars shifted to higher wavenumbers indicating that the bond length of hydroxyl groups decreases. ${ }^{42}$ The decreasing bond length might occur due to environmental factors such as temperature and concentration. ${ }^{42}$ The peaks of Mg-treated biochar imply that Mg particles do not influence the structure of organic functional groups in Mg-treated biochar. ${ }^{43}$ Extra $\mathrm{OH}$ was generated on Mg-treated biochar, which may be accountable for the adsorption ability of biochar. ${ }^{17}$

Surface area and pore volume are parts of the essential characteristics for any carbon adsorbents to reflect its adsorptive capacity. ${ }^{44} \mathrm{Mg}$-treated PKS biochar was able to show the highest surface area, which might be due to several mechanisms that had occurred on the biochar surface ${ }^{45}$. This research showed a similar result where MgO-treated corncob biochar $\left(26.56 \mathrm{~m}^{2} \mathrm{~g}^{-1}\right)$ has a higher surface area than corncob biochar $\left(0.07 \mathrm{~m}^{2} \mathrm{~g}^{-1}\right) .^{45}$

Volatile matters discharged during carbonization assist the pore formation in the biochar structure ${ }^{39}$. Besides, chemical activation and high carbonization temperature affect the size of the surface area of biochar, which leads to the creation of additional biochar pores. ${ }^{39}$ However, a few studies displayed different results. The surface area of Mg-treated biochars is smaller than the untreated biochar due to the accumulation of $\mathrm{Mg}$ elements on the biochar surface. ${ }^{29,43} \mathrm{Mg}$-treated biochar made from PKS displayed a relatively large surface area compared to other feedstocks such as corncob and wood chips, where at least numerous of them are below $<500 \mathrm{~m}^{2} \mathrm{~g}$ ${ }^{1} .{ }^{17}$ All chemically treated biochar also presented a slight prominent increase in the pore volume, indicating that the ethanol, methanol, and magnesium treatment could increase the biochar porosity.

The differences in MB removal efficiencies for all biochars are notable as untreated PKS biochar has the lowest removal efficiency, followed by EtOH-treated PKS biochar, $\mathrm{MeOH}-$ treated PKS biochar, and Mg-treated PKS biochar with a probable reason due to the differences in surface areas and total pore volume (Table 1). Biochars that have large surface areas and pore volumes indicate that the biochar has more pores, leading to the formation of additional active sites for the adsorption to happen. ${ }^{46}$ Other than that, the highest MB removal efficiency for all biochars took place at the highest initial concentration in this study ${ }^{46,47}$, which is $7 \mathrm{ppm}$. The higher concentration is believed to supply a driving force to surmount all bulk transfer resistances between all particles in aqueous solution and solid phases ${ }^{47}$ The escalation in MB removal percentage as the initial concentration increased might be instigated by the exchanges or interactions between $\mathrm{MB}$ ions and the active sites of biochar. ${ }^{48}$ The higher the MB concentration, the higher the quantity of MB ions in the mixture. Thus, the greater the adsorption of MB takes place on the adsorbent's adsorption site. ${ }^{49}$

However, the surface area is not the only biochar properties that influence MB removal efficiency. Surface functionality is also vital in facilitating the adsorption between the adsorbate and the adsorbent. ${ }^{46}$ Adsorption of contaminants from aqueous solution by adsorbents is caused by chemical interactions such as electrostatic interaction, cation exchange, and surface precipitation ${ }^{46}$. The bands that are slightly shifted to a new one (lower or higher wavenumber) in biochar, demonstrating that chemical interactions had occurred on the treated biochar surface. ${ }^{32}$

The treatment of PKS biochar using EtOH and $\mathrm{MeOH}$ has altered and enhanced the O-containing functional groups on the biochar surface, which is following the study by Jing et al. ${ }^{14}$. In the case of EtOH-treated PKS biochar and $\mathrm{MeOH}-$ treated PKS biochar, one of the essential mechanisms that could happen between the positively charged MB and the negatively charged biochar is electrostatic interaction. Based on the adsorption experiment in the present study, the MB removal efficiencies for both EtOH-treated PKS biochar and $\mathrm{MeOH}$-treated PKS biochar are higher than that of untreated PKS biochar hence, implying that the surface of EtOH-treated PKS biochar and MeOH-treated PKS biochar had been enriched with more carboxyl groups and hydroxyl groups for more chemical interactions to occur ${ }^{32}$. This can be seen in Table 2 where both $\mathrm{MeOH}$-treated PKS biochar and EtOHtreated PKS biochar shifted to a higher wavenumber than untreated PKS biochar.

As for Mg-treated PKS biochar, since Mg is a positively charged compound similar to $\mathrm{MB}$, repulsion might occur between $\mathrm{Mg}$ and MB. However, based on the removal efficiency result of Mg-treated PKS biochar (Figure 2), the biochar treatment using $\mathrm{Mg}$ has the highest removal efficiency. This further implies that electrostatic interaction might occur between Mg-treated PKS biochar and MB, which explained the bands' shifts. Apart from that, cation exchange might be one of the prominent mechanisms included in $\mathrm{MB}$ adsorption onto PKS biochar, which also shifted the bands. ${ }^{28,50} \mathrm{MB}$ is widely used as a standard reagent for cation exchange determination in soil..$^{50}$ From Table 2, the band spectra representing the hydroxyl group shifted to higher wavenumbers with a plausible reason because of the increase in the interactions between the hydroxyl group of the biochar and MB. ${ }^{32,42} \mathrm{Ad}-$ sorption of $\mathrm{MB}$ via cation exchange could happen when $\mathrm{Mg}$ compounds on the biochar surface are released and replaced with MB. Besides, intraparticle diffusion and pore diffusion might also occur during the adsorption of MB onto all chemically modified biochar. ${ }^{28,51}$ 
Several previous studies show a similar increment trend for removing $\mathrm{MB}$ on the surface of biochar produced from numerous feedstocks. ${ }^{1,20,24}$ However, a few types of research displayed a declining trend for percentage removal of $\mathrm{MB}$, probably due to different adsorbents and parameters used. ${ }^{20}$ In terms of adsorption, the curves were smoothly increasing up to the point of saturation and started to remain stable afterward. ${ }^{1,34,35}$ This might be attributed to the great exposure of the adsorption spots on the adsorbents. ${ }^{33}$ There is no remarkable contrast between MB removal percentages by all treated biochar at $30 \mathrm{~min}, 45 \mathrm{~min}$, and $60 \mathrm{~min}$ though all percentages keep on increasing when the contact time increases. This, however, implies that the MB removal percentage can reach $100 \%$ if a longer contact time is taken.

Langmuir isotherm functions based on the supposition that monolayer adsorption occurs with homogenous binding sites and energy levels, with no interactions between adsorbed particles on the surface of adsorbents. ${ }^{52}$ In other words, the instant an adsorbate particle fills up a site, there would be no further adsorption can occur. ${ }^{53}$ Langmuir isotherm was tested for MB removal by untreated PKS biochar, EtOH-treated PKS biochar, $\mathrm{MeOH}$-treated PKS biochar, and Mg-treated PKS biochar. A linear plot of $\mathrm{C}_{\mathrm{e}} / \mathrm{q}_{\mathrm{e}}$ against $\mathrm{C}_{\mathrm{e}}$ was drawn to evaluate the $\mathrm{MB}$ adsorption equilibrium with all biochar.

The $\mathrm{R}^{2}$ value indicates that the adsorption data for MB removal by all adsorbents is not appropriate with the Langmuir model as $\mathrm{R}^{2}$ values for all adsorbents are comparatively low and distant from 1. Hence, it is observed that Langmuir isotherm is unsuitable for defining adsorption characteristics of untreated PKS biochar, EtOH-treated PKS biochar, $\mathrm{MeOH}-$ treated PKS biochar, and Mg-treated PKS biochar. However, a few studies showed opposite results where the MB adsorption was able to fit Langmuir isotherm. An earlier study by Savran et al. ${ }^{52,53}$ exhibited that adsorption data for MB by $\mathrm{Pa}$ liurus Spina-Christi fruits and seeds fitted well with Langmuir isotherm. Since all biochar from this study does not fit with the Langmuir isotherm graph, the adsorption of MB was said not to be limited to only monolayer adsorption. ${ }^{54}$

The Freundlich isotherm was tested based on the adsorption experiment for MB. This model is primarily utilized in the heterogeneous system, particularly for extremely interactive molecules on the adsorbent's surface ${ }^{36}$. Constant $n$ suggests the favourability of the adsorption system ${ }^{36}$. The adsorption is considered to be favourable when the value of $n$ is between 1 and $10^{55}$. When the $n$ value is high, it is regarded as beneficial adsorption throughout the whole range of concentration. In contrast, a low value of $n$ gives an implication of useful adsorption at high concentrations but less favourable at lower concentrations ${ }^{56}$. In the current work, the values of $n$ for all biochar are below 1 . Therefore, it is implied that the adsorption of MB at low concentrations is unfavourable. $1 / n$ is the measure of heterogeneity factor of the surface of adsorbents, ranging between 0 and 1 , where $1 / n<1$ suggests that normal adsorption or chemisorption has occurred while $1 / n>1$ provides implication of cooperative adsorption. ${ }^{57}$ In the case of the current study, it can be observed that the value of $1 / n$ for Mg-treated PKS biochar is -5.6699 , indicating that the type of adsorption that might take place on the biochar surface is chemisorptions. ${ }^{56,57}$ The value of the coefficient of determination, $\mathrm{R}^{2}$ for $\mathrm{MB}$ adsorption by untreated PKS biochar is 0.9306 , and the value of $\mathrm{R}^{2}$ for EtOH-treated PKS biochar is 0.7291. MeOH-treated PKS biochar and Mgtreated PKS biochar have $\mathrm{R}^{2}$ of 0.6545 and 0.5370 , respectively. From these results, Freundlich isotherm also is not fit to define the adsorption attributes of MB by PKS biochar as compared to Langmuir isotherm. However, there is a possibility for Mg-treated PKS biochar can be explained by other isotherms models such as Tempkin and Dubinin-KaganerRadushkevich. ${ }^{58,59}$

\section{CONCLUSION}

The current study showed that PKS biochar treated using $\mathrm{EtOH}, \mathrm{MeOH}$, and $\mathrm{Mg}$ can be employed as a sorbent to eradicate MB from an aqueous solution. The surface area for all biochar, as shown in BET analysis, indeed increased after the carbonization and modification of biochar, ranging from $0.848 \mathrm{~m}^{2} \mathrm{~g}^{-1}$ to $674 \mathrm{~m}^{2} \mathrm{~g}^{-1}$. The highest percentage removals of MB onto all biochar were $93.12 \%, 94.79 \%, 95.79 \%$, and $98.51 \%$, which occurred at an initial concentration of $7 \mathrm{ppm}$. Results suggested that the $\mathrm{EtOH}, \mathrm{MeOH}$, and $\mathrm{Mg}$ treated PKS biochar can potentially function as an adsorbent in removing dye from wastewater.

\section{ACKNOWLEDGEMENT}

Authors acknowledge the immense help received from the scholars whose articles are cited and included in references to this manuscript. The authors are also grateful to authors/ editors/publishers of all those articles, journals and books from where the literature for this article has been reviewed and discussed.

Source of Funding: Ministry of Higher Education Malaysia (Fundamental Research Grant Scheme (FRGS), Grant No.: F07/FRGS/1494/2016).

Conflict of Interest: We do not have any conflict of interest (financial or other) other than those declared.

\section{Authors' Contributions:}

NHH: Conducting laboratory work, data analysis, and drafting the article

RW: Conception of the work and critical revision of the article

YY: Data interpretation, and critical revision of the article. 


\section{REFERENCES}

1. Jawad AH, Rashid RA, Ishak MA, Wilson LD. Adsorption of methylene blue onto activated carbon developed from biomass waste by $\mathrm{H} 2 \mathrm{SO} 4$ activation: kinetic, equilibrium and thermodynamic studies. Desalin Water Treat 2016;57(52):25194-25206.

2. García JR, Sedran U, Zaini MA, Zakaria ZA. Preparation, characterization, and dye removal study of activated carbon prepared from palm kernel shell. Environ Sci Pollut Res 2018;25(6):50765085.

3. Vikrant K, Giri BS, Raza N, Roy K, Kim KH, Rai BN, Singh RS. Recent advancements in bioremediation of dye: current status and challenges. Bioresour Technol 2018;253:355-367.

4. Jia P, Tan H, Liu K, Gao W. Removal of methylene blue from aqueous solution by bone char. Appl Sci 2018;8(10):1903.

5. Karaer H, Kaya I. Synthesis, characterization of magnetic chitosan/active charcoal composite and using at the adsorption of methylene blue and reactive blue4. Micropor Mesopor Mat 2016;232:26-38.

6. Gouamid MO, Ouahrani MR, Bensaci MB. Adsorption equilibrium, kinetics and thermodynamics of methylene blue from aqueous solutions using date palm leaves. Energy Procedia 2013;36:898-907.

7. Abechi SE, Gimba CE, Uzairu A, Kagbu JA, Ocholi OJ. Equilibrium adsorption studies of methylene blue onto palm kernel shell-based. Int J Eng Sci 2013;2(5):38-45.

8. Mousavi SA, Mehralian M, Khashij M, Parvaneh S. Methylene Blue removal from aqueous solutions by activated carbon prepared from N. microphyllum (AC-NM): RSM analysis, isotherms and kinetic studies. Glob Nest J 2017;19(4):697-705.

9. Igwe JC, Abia AA. Adsorption isotherm studies of $\mathrm{Cd}$ (II), $\mathrm{Pb}$ (II) and $\mathrm{Zn}$ (II) ions bioremediation from aqueous solution using unmodified and EDTA-modified maize cob. Eclética Quim J 2007;32(1):33-42.

10. Liao P, Ismael ZM, Zhang W, Yuan S, Tong M, Wang K, Bao J. Adsorption of dyes from aqueous solutions by microwave modified bamboo charcoal. Chem Eng J 2012;195:339-346.

11. Tan X, Liu Y, Zeng G, Wang X, Hu X, Gu Y, Yang Z. Application of biochar for the removal of pollutants from aqueous solutions. Chemosphere 2015;125:70-85.

12. Mohan MA, Chadaga M. Methylene blue colour removal using physically and chemically activated cashew nut shell activated carbon. Int J Technol Enhanc Emerg Eng Res 2014;2:64-69.

13. Niran OB, Olawale SA, Ushie UJ. Isotherm studies of adsorption of methylene blue by palm kernel shell. Asian J Appl Chem Res 2018;1(1):1-9.

14. Jing XR, Wang YY, Liu WJ, Wang YK, Jiang H. Enhanced adsorption performance of tetracycline in aqueous solutions by methanol-modified biochar. Chem Eng J 2014;248:168-174.

15. Kousha M, Daneshvar E, Sohrabi MS, Jokar M, Bhatnagar A. Adsorption of acid orange II dye by raw and chemically modified brown macroalga Stoechospermum marginatum. Chem Eng J 2012;192:67-76.

16. Rubin E, Rodriguez P, Herrero R, Sastre de Vicente ME. Adsorption of methylene blue on chemically modified algal biomass: Equilibrium, dynamic, and surface data. J Chem Eng Data 2010;55(12):5707-5714.

17. Zhao X, Yi S, Dong S, Xu H, Sun Y, Hu X. Removal of Levofloxacin from aqueous solution by Magnesium-impregnated Biochar: batch and column experiments. Chem Special Bioavailab 2018;30(1):68-75.

18. Sartape A, Mandhare A, Salvi P, Pawar D, Prakash RA, Anuse M, Kolekar S. Removal of Bi (III) with adsorption tech- nique using coconut shell activated carbon. Chin J Chem Eng 2012;20(4):768-775.

19. Sukiran MA, Bakar NK, Chin CM. Optimization of pyrolysis of oil palm empty fruit bunches. J Oil Palm Res 2009;21:653-8.

20. Fatiha M, Belkacem B. Adsorption of methylene blue from aqueous solutions using natural clay. J Mater Environ Sci 2016;7(1):285-292.

21. Tengku Hasbullah TNA, Selaman OS, Rosli NA. Removal of Methylene Blue from Aqueous Solutions using Chemical Activated Carbon Prepared from Jackfruit (Artocarpusheterophyllus) Peel Waste. Int J Civ Eng Technol 2014;5(1):34-38.

22. Gnanasundaram N, Loganathan M, Singh A. Optimization and performance parameters for adsorption of $\mathrm{Cr}^{6+}$ by microwave assisted carbon from Sterculia foetida shells. Mater Sci Eng C 2017;206(1);1-10.

23. Edokpayi O, Osemwenkhae O, Ayodele BV, Ossai J, Fadilat SA, Ogbeide SE. Batch adsorption study of methylene blue in aqueous solution using activated carbons from rice husk and coconut shell. J Appl Sci Environ 2018;22(5):631-635.

24. Shaid MS, Zaini MA, Nasri NS. Isotherm studies of methylene blue adsorption onto waste tyre pyrolysis powder-based activated carbons. Mal J Fund Appl Sci 2017;13(4):671-675.

25. Peiris C, Gunatilake SR, Mlsna TE, Mohan D, Vithanage M. Biochar based removal of antibiotic sulfonamides and tetracyclines in aquatic environments: a critical review. Bioresour Technol 2017;246:150-159.

26. Ayawei N, Ebelegi AN, Wankasi D. Modelling and interpretation of adsorption isotherms. J Chem 2017; 3039817.

27. Rezaee A, Rangkooy HA, Khavanin A, Jonidi-Jafari A, Soltani RD, Nili-Ahmadabadi A. Adsorption properties and breakthrough model of formaldehyde on bone char. IJESD 2011;2(6):423.

28. Fan S, Tang J, Wang Y, Li H, Zhang H, Tang J, Wang Z, Li X. Biochar prepared from co-pyrolysis of municipal sewage sludge and tea waste for the adsorption of methylene blue from aqueous solutions: kinetics, isotherm, thermodynamic and mechanism. J Mol Liq 2016;220:432-441.

29. Riddle M, Bergström L, Schmieder F, Lundberg D, Condron L, Cederlund H. Impact of biochar coated with magnesium (hydr) oxide on phosphorus leaching from organic and mineral soils. J Soils Sediments 2019;19(4):1875-1889.

30. Liew RK, Nam WL, Chong MY, Phang XY, Su MH, Yek PN, Ma NL, Cheng CK, Chong CT, Lam SS. Oil palm waste: an abundant and promising feedstock for microwave pyrolysis conversion into good quality biochar with potential multi-applications. Process Saf Environ 2018;115:57-69.

31. Johari K, Saman N, Tien SS, Chin CS, Kong H, Mat H. Removal of elemental mercury by coconut pith char adsorbents. Procedia engineering. 2016;148:1357-1362.

32. Komnitsas KA, Zaharaki D. Morphology of modified biochar and its potential for phenol removal from aqueous solutions. Front Environ Sci 2016;4:26.

33. Ben-Ali S, Jaouali I, Souissi-Najar S, Ouederni A. Characterization and adsorption capacity of raw pomegranate peel biosorbent for copper removal. J Clean Prod 2017;142:3809-3821.

34. Kristanti RA, Kamisan MK, Hadibarata T. Treatability of methylene blue solution by adsorption process using Neobalanocarpus hepmii and Capsicum annuum. Water Air Soil Pollut 2016;227(5):134.

35. Mathew M, Desmond RD, Caxton M. Removal of methylene blue from aqueous solutions using biochar prepared from Eichhorrnia crassipes (Water Hyacinth)-molasses composite: Kinetic and equilibrium studies. Afr J Pure Appl Chem 2016;10(6):6372 . 
36. Savran A, Selçuk NC, Kubilay S, Kul A. Adsorption isotherm models for dye removal by paliurus spinachristi mill. frutis and seeds in a single component system. J Environ Sci Toxicol Food Technol 2017;11(4):18-30.

37. Patel B, Gami B. Biomass characterization and its use as solid fuel for combustion. Iranica Energ Environ Sci 2012;3(2):123128.

38. Pinto MD, da Silva DD, Gomes AL, dos Santos RM, de Couto RA, de Novais RF, Constantino VR, Tronto J, Pinto FG. Biochar from carrot residues chemically modified with magnesium for removing phosphorus from aqueous solution. J Clean Prod 2019;222:36-46.

39. Antunes E, Jacob MV, Brodie G, Schneider PA. Silver removal from aqueous solution by biochar produced from biosolids via microwave pyrolysis. J Environ Manage 2017;203:264-272.

40. Liu WJ, Jiang H, Yu HQ. Development of biochar-based functional materials: toward a sustainable platform carbon material. Chem Rev 2015 Nov 25;115(22):12251-12285.

41. Wahi R, Aziz SM, Hamdan S, Ngaini Z. Biochar production from agricultural wastes via low-temperature microwave carbonization. IEEE International RF and Microwave Conference (RFM); 2015 Dec 14; Kuching, Sarawak. p. 244-247.

42. Coates J. Interpretation of infrared spectra, a practical approach. Encyclopedia of analytical chemistry: applications, theory and instrumentation. 2006 Sep 15.

43. Fang C, Zhang T, Li P, Jiang RF, Wang YC. Application of magnesium modified corn biochar for phosphorus removal and recovery from swine wastewater. Int J Environ Res 2014;11(9):9217-9237.

44. He R, Peng Z, Lyu H, Huang H, Nan Q, Tang J. Synthesis and characterization of an iron-impregnated biochar for aqueous arsenic removal. Sci Total Environ 2018;612:1177-1186.

45. Shen Z, Zhang J, Hou D, Tsang DCW, Ok YS, Alessi DS. Synthesis of $\mathrm{MgO}$-coated corncob biochar and its application in lead stabilization in a soil washing residue. Environ Int 2018;122:357-362.

46. Sizmur T, Fresno T, Akgül G, Frost H, Moreno-Jiménez E. Biochar modification to enhance sorption of inorganics from water. Bioresour Technol 2017;246:34-47.

47. Gupta VK, Ganjali MR, Nayak A, Bhushan B, Agarwal S. Enhanced heavy metals removal and recovery by mesoporous adsorbent prepared from waste rubber tire. Chem Eng J 2012;197:330-342.

48. Suhada N, Tahiruddin NS, Zubaidah S, Ab Rahman SZ. Adsorption of lead in aqueous solution by a mixture of activated char- coal and peanut shell. World J Sci Technol Res 2013;1(5):102109.

49. Pathania D, Sharma S, Singh P. Removal of methylene blue by adsorption onto activated carbon developed from Ficus carica bast. Arab J Chem 2017;10:S1445-1451.

50. Zhu S, Fang S, Huo M, Yu Y, Chen Y, Yang X, et al. A novel conversion of the groundwater treatment sludge to magnetic particles for the adsorption of methylene blue. J Hazard Mater 2015;292:173-179.

51. Mahmoudi K, Hamdi N, Srasra E. Study of adsorption of methylene blue onto activated carbon from lignite. Surf Eng Appl Electrochem 2015;51(5):427-433.

52. Inyinbor AA, Adekola FA, Olatunji GA. Kinetics, isotherms and thermodynamic modeling of liquid phase adsorption of Rhodamine B dye onto Raphia hookerie fruit epicarp. Water Resour Ind 2016;15:14-27.

53. Foo KY, Hameed BH. Insights into the modeling of adsorption isotherm systems. Chem Eng J 2010;156(1):2-10.

54. Onyeji LI, Aboje AA. Removal of heavy metals from dye effluent using activated carbon produced from coconut shell. Int J Engin Sci Technol 2011;3(12):8238-8246.

55. El Haddad M. Removal of Basic Fuchsin dye from water using mussel shell biomass waste as an adsorbent: Equilibrium, kinetics, and thermodynamics. J Taibah Univ Sci 2016;10(5):664674.

56. Ghaedi M, Heidarpour S, Kokhdan SN, Sahraie R, Daneshfar A, Brazesh B. Comparison of silver and palladium nanoparticles loaded on activated carbon for efficient removal of methylene blue: kinetic and isotherm study of the removal process. Powder Technol 2012;228:18-25.

57. Dada AO, Olalekan AP, Olatunya AM, Dada OJ. Langmuir, Freundlich, Temkin and Dubinin-Radushkevich isotherms studies of equilibrium sorption of $\mathrm{Zn} 2+$ unto phosphoric acid modified rice husk. IOSR-JAC 2012 Nov;3(1):38-45.

58. Lekene Ngouateu RB, Kouoh Sone PMA, Ndi Nsami J, Kouotou D, Belibi Belibi PD, Ketcha Mbadcam J.. Kinetics and equilibrium studies of the adsorption of phenol and methylene blue onto cola nut shell based activated carbon. Int J Curr Res Rev 2015;7(9):1-9.

59. Oguegbulu EN, Nwokeboth EA. Evaluation of the effects of ph and temperature on the adsorption isotherm of activated medicoal from Nigeria plants Magniferaindica, Perseagratissima and Psidiumguajava. Int J Curr Res Rev 2016;8(6):18-21.

Table 1: Surface area and total pore volume for raw PKS, untreated PKS biochar, MeOH-treated PKS biochar, EtOH-treated PKS biochar and Mg-treated PKS biochar

\begin{tabular}{lccccc} 
Sample & Raw PKS & $\begin{array}{c}\text { Untreated PKS } \\
\text { biochar }\end{array}$ & $\begin{array}{c}\text { EtOH-treated PKS } \\
\text { biochar }\end{array}$ & $\begin{array}{c}\text { MeOH-treated PKS } \\
\text { biochar }\end{array}$ & $\begin{array}{c}\text { Mg-treated PKS } \\
\text { biochar }\end{array}$ \\
\hline $\begin{array}{l}\text { Surface area }\left(\mathrm{m}^{2} \mathrm{~g}^{-1}\right) \\
\text { Total pore volume }\end{array}$ & 0.848 & 592 & 647 & 663 & 674 \\
$(\mathrm{~cm} / \mathrm{g})$ & 0.003 & 0.353 & 0.394 & 0.404 & 0.424 \\
\hline
\end{tabular}


Table 2: FTIR spectra band assignments

\begin{tabular}{|c|c|c|c|c|c|c|}
\hline \multirow{2}{*}{$\begin{array}{l}\text { Wavenumber } \\
\left(\mathrm{cm}^{-1}\right)\end{array}$} & \multirow[t]{2}{*}{ Assignments } & \multicolumn{5}{|c|}{ Wavenumber of samples $\left(\mathrm{cm}^{-1}\right)$} \\
\hline & & Raw PKS & $\begin{array}{c}\text { Untreated PKS } \\
\text { Biochar }\end{array}$ & $\begin{array}{l}\text { MeOH-treated } \\
\text { PKS biochar }\end{array}$ & $\begin{array}{l}\text { EtOH-treated } \\
\text { PKS biochar }\end{array}$ & $\begin{array}{l}\text { Mg-treated } \\
\text { PKS biochar }\end{array}$ \\
\hline $3500-3200$ & $\begin{array}{l}\text { O-H stretching indica- } \\
\text { tive of alcohol, phenol or } \\
\text { carboxylic acid }\end{array}$ & 3452.86 & 3449.85 & 3452.82 & 3453.87 & 3455.23 \\
\hline $1700-1600$ & $\begin{array}{l}\mathrm{C}=\mathrm{O} \text { or } \mathrm{C}=\mathrm{C} \text { stretching in } \\
\text { aromatic ring or alkenes }\end{array}$ & 1650.47 & 1646.50 & 1649.94 & 1649.67 & 1646.46 \\
\hline $1500-1300$ & $\begin{array}{l}\mathrm{C}-\mathrm{H}\left(\mathrm{CH}_{2} \text { and } \mathrm{CH}_{3}\right) \text { bend- } \\
\text { ing in alkanes }\end{array}$ & 1407.81 & 1389.21 & 1389.47 & 1388.26 & 1390.22 \\
\hline $900-600$ & $\begin{array}{l}\mathrm{C}-\mathrm{H} \text { bending vibrations in } \\
\text { aromatic compounds }\end{array}$ & 612.14 & 672.03 & $\begin{array}{l}841.64 \\
672.51\end{array}$ & $\begin{array}{c}840.03 \\
611.81\end{array}$ & $605 \cdot 57$ \\
\hline
\end{tabular}

Table 3: Adsorption isotherms parameters for MB removal by untreated PKS biochar, EtOH-treated PKS biochar, MeOH-treated PKS biochar and Mg-treated PKS biochar

\begin{tabular}{llcccc} 
Isotherm models & Parameters & \multicolumn{4}{c}{ Adsorbents } \\
& & $\begin{array}{c}\text { Untreated PKS } \\
\text { Biochar }\end{array}$ & $\begin{array}{c}\text { EtOH-treated } \\
\text { PKS Biochar }\end{array}$ & $\begin{array}{c}\text { MeOH-treated } \\
\text { PKS Biochar }\end{array}$ & $\begin{array}{c}\text { Mg-treated PKS } \\
\text { Biochar }\end{array}$ \\
Langmuir & $\mathrm{q}_{\mathrm{m}}(\mathrm{mg} / \mathrm{g})$ & -0.08628 & -0.2776 & -0.4773 & 0.06126 \\
& $\mathrm{~K}_{\mathrm{L}}(\mathrm{L} / \mathrm{mg})$ & -1.9694 & -2.2702 & -2.1893 & -10.0635 \\
& $\mathrm{R}^{2}$ & 0.7124 & 0.3507 & 0.3806 & 0.5669 \\
\hline \multirow{2}{*}{ Freundlich } & $\mathrm{H}$ & 5.5926 & 2.6258 & 2.0226 & -5.6699 \\
& $\mathrm{l} / \mathrm{n}$ & 0.1766 & 0.3808 & 0.4944 & -0.1764 \\
& $\mathrm{n}$ & 69.2309 & 16.9122 & 11.0943 & $2.8536 \times 10^{-6}$ \\
& $\mathrm{~K}_{\mathrm{F}}(\mathrm{mg} / \mathrm{g})$ & 0.9306 & 0.7291 & 0.6545 & 0.5370 \\
\hline
\end{tabular}

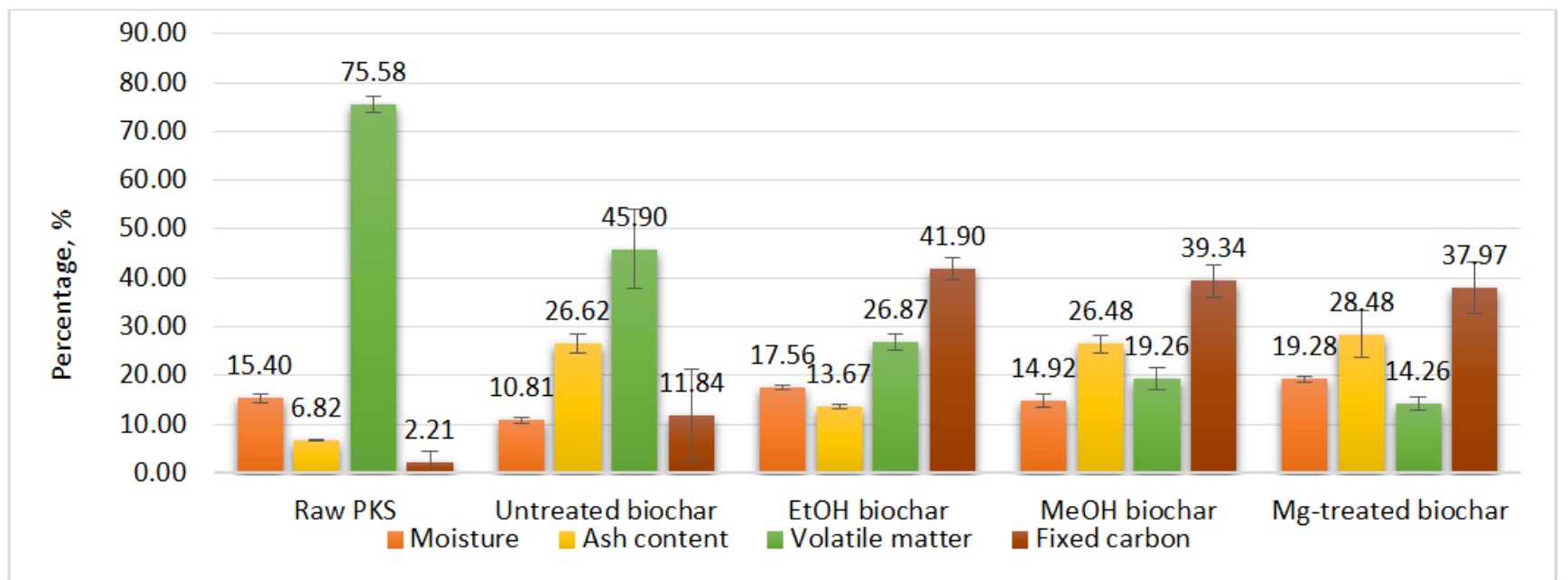

Figure 1: Proximate analysis of raw PKS, untreated PKS biochar, EtOH-treated PKS biochar, $\mathrm{MeOH}$-treated PKS biochar and Mg-treated PKS biochar. 


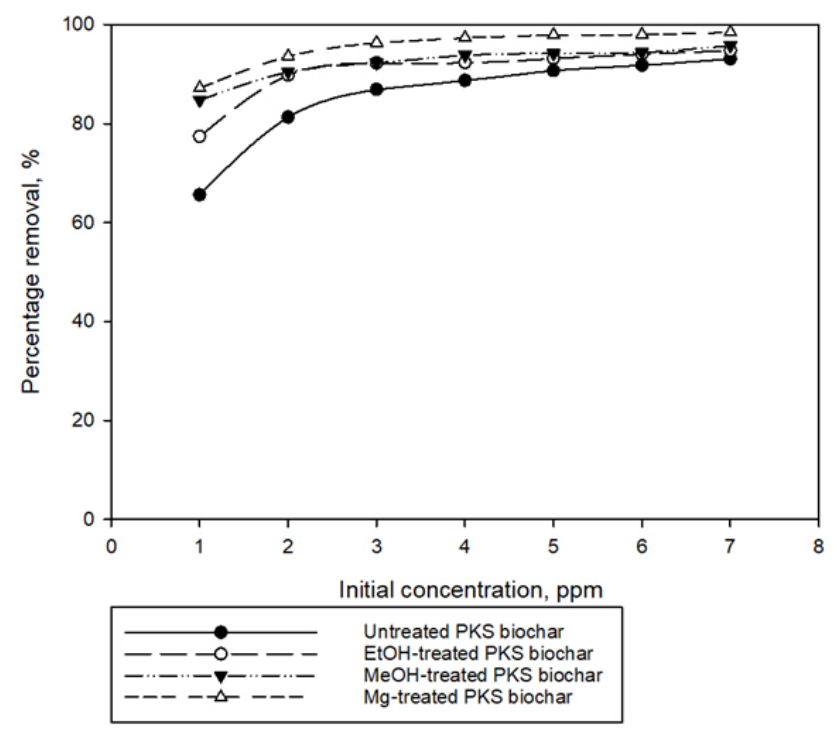

Figure 2: Effect of initial concentration on MB removal by untreated PKS biochar, EtOH-treated PKS biochar, MeOH-treated PKS biochar and Mg-treated PKS biochar.

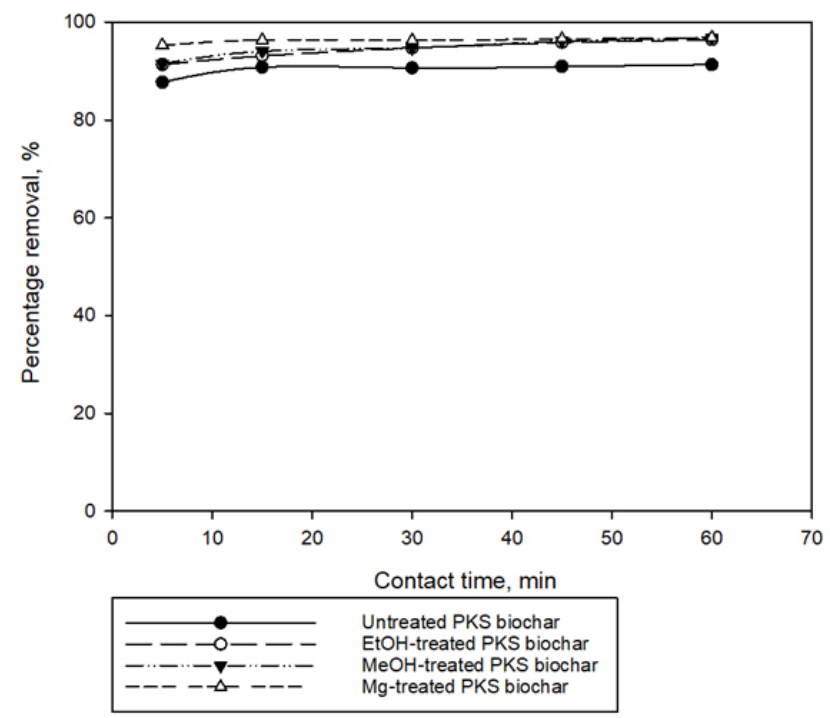

Figure 3: Effect of contact time on MB removal by untreated PKS biochar, EtOH-treated PKS biochar, MeOH-treated PKS biochar and Mg-treated PKS biochar.

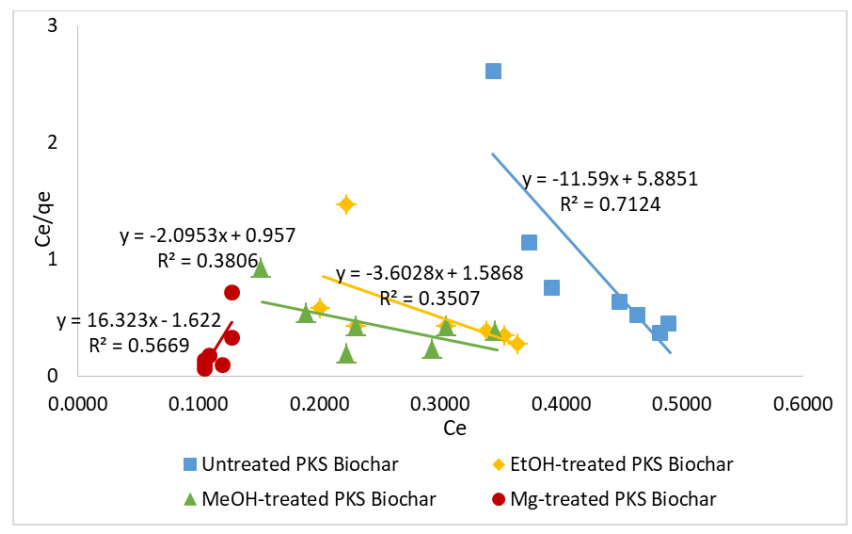

Figure 4: Langmuir isotherm plot for MB removal by untreated PKS biochar, EtOH-treated PKS biochar, MeOH-treated PKS biochar and Mg-treated PKS biochar.

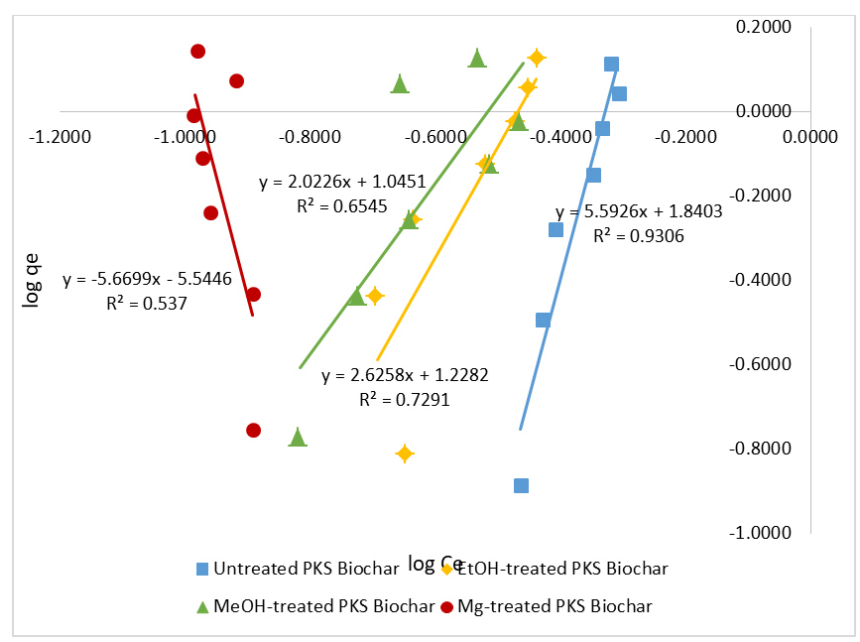

Figure 5: Freundlich isotherm plot for MB removal by untreated PKS biochar, EtOH-treated PKS biochar, $\mathrm{MeOH}$-treated PKS biochar and Mg-treated PKS biochar. 